\title{
Medical device design for adolescent adherence and developmental goals: a case study of a cystic fibrosis physiotherapy device
}

This article was published in the following Dove Press journal:

Patient Preference and Adherence

17 March 2014

Number of times this article has been viewed

\author{
Alexandra R Lang' \\ Jennifer L Martin ${ }^{2}$ \\ Sarah Sharples' \\ John A Crowe ${ }^{3}$
}

'Human Factors Research Group, Faculty of Engineering, University of Nottingham, Nottingham, UK; ${ }^{2}$ Mindtech Healthcare Technology Cooperative (Htc), Faculty of Medicine and Health Sciences, Institute of Mental Health, Nottingham, UK; ${ }^{3}$ Biomedical Engineering, Faculty of Engineering, University of Nottingham, UK
Correspondence: Alexandra R Lang Human Factors Research Group, Faculty of Engineering, Room B03, Innovative Technologies Research Centre (ITRC), University Park, University of Nottingham, Nottingham, NG7 2RD, UK Tel +44 792I 912376

Email alexandra.lang@nottingham.ac.uk
Purpose: This study investigates the psychosocial aspects of adolescent medical device use and the impact on adolescent adherence and goals for the transitional years between child and adulthood.

Patients and methods: Interviews were carried out with 20 adolescents with cystic fibrosis, investigating adolescent medical device use and experiences in relation to their personal and social lives and development through the adolescent years. The qualitative dataset was thematically examined using a content analysis method.

Results: The results show that adolescent users of medical technologies want their independence and capabilities to be respected. Adolescent adherence to medical device use was associated with short- and long-term motivations, where older adolescents were able to comprehend the longerterm benefits of use against short-term inconvenience more acutely than younger adolescents. It was suggested that medical devices could provide a tool for communication with families and clinicians and could support adolescents as they take responsibility for managing their condition. Themes of "fitting into teenage life" and "use in the community" were associated with adolescents' needs to form their own identity and have autonomy.

Conclusion: This study shows that adolescent needs regarding medical device use are complex. It provides evidence to suggest that devices designed inclusively for adolescents may lead to improved adherence and also facilitate transition through the adolescent years and achievement of adolescent goals.

Keywords: young people, teenagers, technologies, compliance, transition, user requirements

\section{Introduction}

Medical device users are not homogeneous and therefore it is sometimes relevant to understand the needs of specific populations so that these needs might be met for maximum patient benefit. ${ }^{1}$ Medical device use by adolescents is an area of research that has received little attention, ${ }^{2}$ and, therefore, the needs of this population are not currently well understood. Medical advances, including the provision of clinically effective medical devices, can improve life expectancy for people with chronic conditions, thereby increasing the number of adolescents with chronic conditions, ${ }^{3}$ and, subsequently, the number of younger users of medical devices.

Chronic conditions provide additional complications to the process of transitioning from child to adult. ${ }^{4}$ Figure 1 is a representation of adolescent transition and the associated goals derived from adolescent cognitive and social development literature. ${ }^{5}$

Achieving adolescent goals are as important to adolescents with chronic conditions as to those without; however, transition may be affected by the additional burden of 


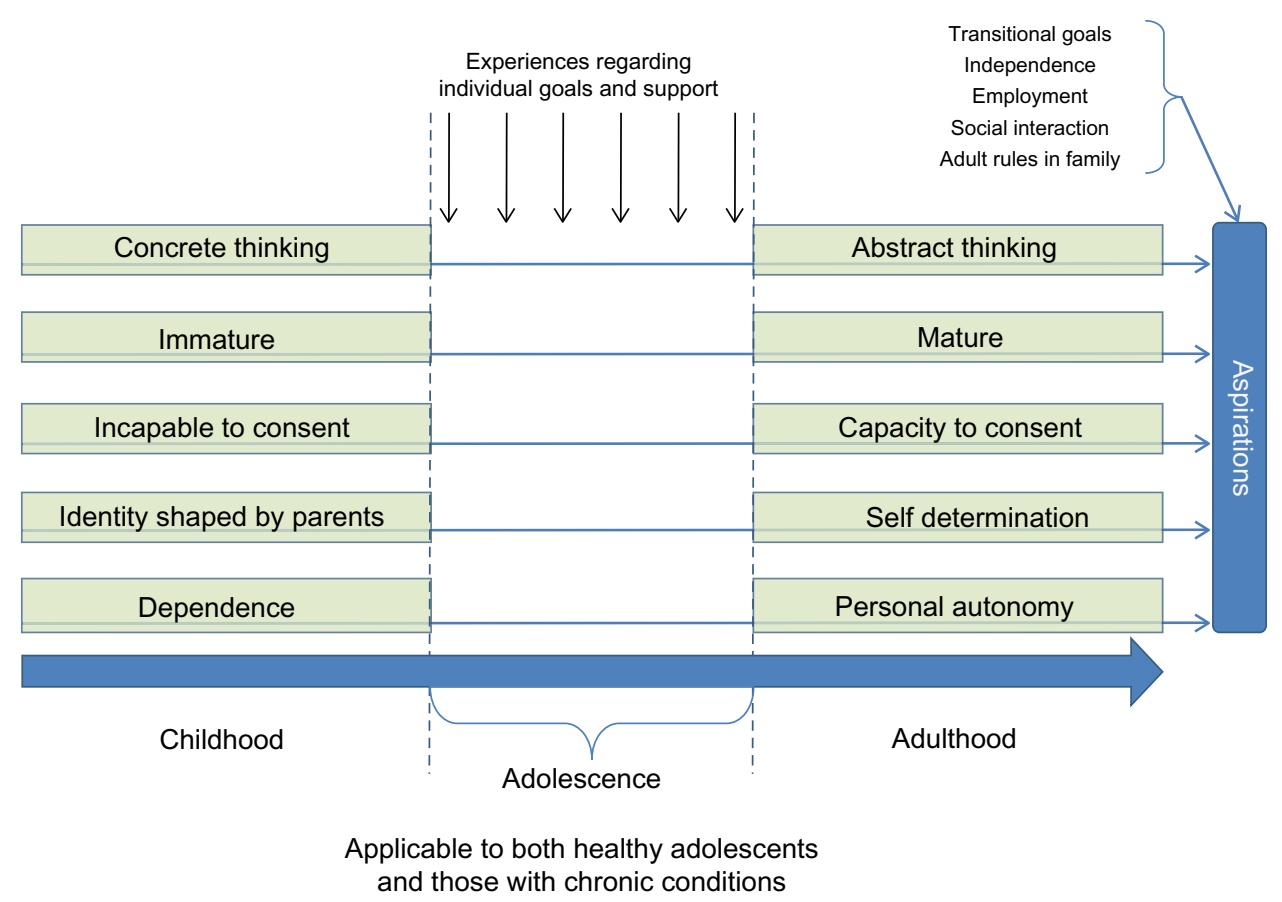

Figure I Adolescent development from child to adult.

disease. ${ }^{6}$ Adolescent health researchers describe how adolescent adherence to treatment regimens is often low and that poor adherence and health behaviors in adolescence are highly indicative of conduct in adulthood ${ }^{7}$ and can therefore be detrimental to long-term health outcomes. ${ }^{8}$

Nonadherence has been described as a "rational choice as patients attempt to maintain their personal identity, achieve their goals, and preserve their quality of life." This demonstrates that adolescent goals are intrinsically linked with the concept of adherence and, as such, medical devices should be developed with an awareness of this issue.

In common with the fact that there is often less consideration of adolescent user requirements of health care services and activities, ${ }^{10}$ there is a statement of need for patient-centered information technologies to assist adolescent health care transitions. ${ }^{11}$ Medical device manufacturers focus predominantly on children, adults, and the elderly in the development and testing of their products. ${ }^{2}$ As a result, adolescents often have to use devices that are designed for adults or children. This raises a number of questions:

- Are these devices appropriate for adolescent users?

- How does the design of these devices affect adherence?

- What role do devices play in adolescent management of chronic conditions?

This paper explores these questions and the relationship between these issues and adolescent developmental goals through a case study of cystic fibrosis (CF) and a medical device - the acapella ${ }^{\circledR}$ (Smiths Medical, St Paul, MN, USA) used to treat this condition.

Please note that this paper considers the general process of development from child to adult. References to "transition" do not refer to the health care transition process defined as the "purposeful, planned movement of adolescents and young adults with chronic physical and medical conditions from child-centered to adult-oriented health care systems." ${ }^{12}$

\section{Cystic fibrosis}

CF affects over 70,000 individuals worldwide and is "the most commonly inherited profoundly life shortening disease." ${ }^{\prime 3}$ Management is burdensome and involves regular drugs and daily airway clearance by physiotherapy. ${ }^{14} \mathrm{CF}$ can significantly affect an adolescent's biological, mental, and psychosocial health ${ }^{6}$ and may affect the goals shown in Figure 1.

\section{Device: the acapella ${ }^{\circledR}$}

Physiotherapy for airway clearance mobilizes mucus from the lungs, helping to reduce infections, and is a critical, but often the most troublesome, aspect of CF management. ${ }^{15}$ Responsibility for this starts with parents and is gradually taken on by the patient during late childhood or early adolescence. ${ }^{16}$ The acapella ${ }^{\circledR}$ (Figure 2 ) is a CF physiotherapy device that is commonly used by adolescents with $\mathrm{CF}$, and for which adherence to use is a known issue. ${ }^{5}$ 


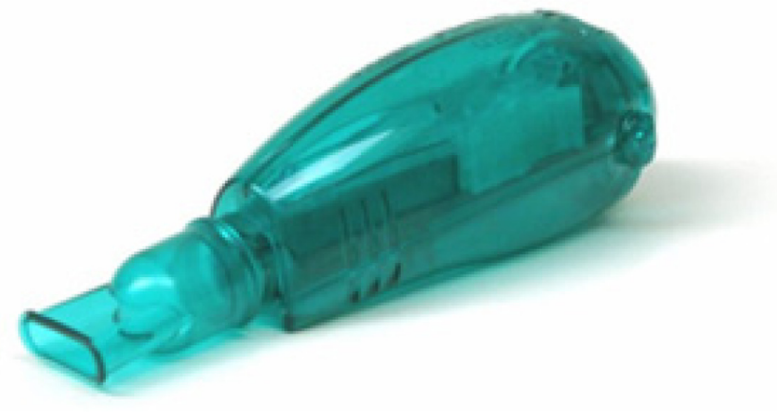

Figure 2 The acapella ${ }^{\circledR}$ physiotherapy device (Smiths Medical, St Paul, MN, USA).

\section{Methods}

Twenty participants were recruited using purposive sampling from pediatric and adult CF clinics within a regional UK hospital trust. Eligible participants were aged 11 to 20 years with previous or current experience of the acapella ${ }^{\circledR}$. Participant details are given in Table 1.

The protocol was designed in collaboration with pediatric $\mathrm{CF}$ physiotherapists, and was also informed by previous research. ${ }^{17}$ Pictorial vignettes were used to stimulate the discussion. ${ }^{18}$ Ethical approval for the study was obtained from the UK National Health Service National Research Ethics Service.

The participants had varying experience with the acapella $^{\circledR}$. Two were new ( $<2$ weeks) users. Six participants had experience of using the acapella ${ }^{\circledR}$; ranging from 3 months

Table I Participant details

\begin{tabular}{llll}
\hline Participant no & Sex & Age (years) & $\begin{array}{l}\text { Accompanying } \\
\text { person }\end{array}$ \\
\hline I & M & 20 & Mother \\
2 & F & 20 & Boyfriend \\
3 & M & 19 & Alone \\
4 & M & 18 & Alone \\
5 & F & 13 & Mother \\
6 & M & 15 & Stepfather \\
7 & F & 16 & Mother \\
8 & M & 11 & Father \\
9 & M & 16 & Alone/mother \\
10 & M & 13 & Father \\
11 & M & 11 & Father \\
12 & F & 19 & Boyfriend \\
13 & F & 20 & Mother \\
14 & M & 17 & Father \\
15 & M & 11 & Grandmother \\
16 & F & 14 & Sister \\
17 & M & 20 & Alone \\
18 & M & 20 & Alone \\
19 & M & 20 & Father \\
20 & F & 19 & Alone/boyfriend \\
\hline
\end{tabular}

Abbreviations: $F$, female; $M$, male. to 4 years, but had abandoned it in favor of alternative devices or therapies. All participants had used other physiotherapy devices and airway clearance techniques. Semi-structured interviews (see Table 2 for the interview schedule) took place in the CF clinics or inpatient wards. Informed consent was obtained from participants over 16 years of age. Assent was ensured for participants younger than 16 years, for whom informed consent was obtained from parents/ guardians.

\section{Data analysis}

Content analysis, a quantitative approach to thematic analysis for qualitative data, ${ }^{19}$ was undertaken. Transcription and coding $^{20}$ were performed in NVivo ${ }^{\mathrm{TM}}$ software (version 9; QSR International Pty Ltd, Doncaster, VIC, Australia) until no new associations could be found. The dataset and emergent themes were reviewed by three independent human factor practitioners from the University of Nottingham and reliability of the findings was affirmed by practitioner agreement. In the following sections, "refs" indicates how many data references were coded within a theme.

\section{Results and discussion}

This paper presents the psychosocial aspects of adolescent device use and how these affect adolescent goals. The results of how physical device design affects use are reported elsewhere..$^{21}$

\section{Respecting independence and capabilities}

The data suggest that adolescents with CF want the opportunity to be in control and would like medical devices to help promote their independence. The qualitative responses from the adolescents asserted that the current acapella ${ }^{\circledR}$ design does not facilitate CF management, as there is a lack of feedback mechanisms to support the user in their long term use of the device. Adolescents associated this lack of feedback as being a barrier to their autonomy and independent use of the device, whereby they could not monitor their adherence for personal information nor could they use that information to demonstrate adherence to parents or healthcare professionals. Twelve of the participants reported that functions such as user interfaces and programmable alerts for physiotherapy breathing routines or long term monitoring of duration and frequency of physiotherapy sessions could facilitate independent physiotherapy without monitoring by parents. Blood glucose monitors were cited by participants as devices with functionality that assisted communication and adherence. 
Table 2 Interview schedule

\begin{tabular}{|c|c|c|}
\hline Stage & Description & Materials \\
\hline Pre-interview formalities & $\begin{array}{l}\text { Researcher introduction and a verbal description of the } \\
\text { research project and aims is given. Participant and guardian } \\
\text { (if participant is under } 16 \text { years old) read information } \\
\text { sheets. Questions invited from participants and guardians. } \\
\text { Participants and guardians asked to fill in the informed } \\
\text { consent and assent forms. }\end{array}$ & $\begin{array}{l}\text { Participant information sheets and consent } \\
\text { and assent forms. }\end{array}$ \\
\hline Collection of participant & Questions asked to obtain participant information and & Interview schedule. \\
\hline background information & $\begin{array}{l}\text { background, specifically about experience of other airway } \\
\text { devices. }\end{array}$ & $3 \times$ vignette posters per participant. \\
\hline Review of acapella ${ }^{\circledR}$ device & $\begin{array}{l}\text { Questions designed to critically assess the current } \\
\text { acapella }{ }^{\circledR} \text { device, with each patient using their experiences } \\
\text { to discuss positive and negative aspects of the current } \\
\text { design and to express their preferences. }\end{array}$ & $\begin{array}{l}\text { Individual stationary packs, including a ballpoint } \\
\text { pen, colored marker pens, and pencils. }\end{array}$ \\
\hline $\begin{array}{l}\text { Review and investigation of } \\
\text { adolescent needs regarding } \\
\text { use of medical device }\end{array}$ & $\begin{array}{l}\text { Questions to encourage the participant to think } \\
\text { expansively about design of their medical device and } \\
\text { suggest ideas about how the acapella }{ }^{\circledR} \text { device could better } \\
\text { meet their own needs or the needs of adolescents in } \\
\text { general. Pictorial vignettes of modified fictional acapella }{ }^{\circledR} \\
\text { designs were presented to participants as inspiration. It was } \\
\text { explained that the images were "mock designs" that were } \\
\text { developed from a previous study involving adolescent } \\
\text { students in schools and not real devices. Participants } \\
\text { were encouraged to think about their use of the device } \\
\text { and how it fits in with their lives. During this exercise, } \\
\text { participants were invited to illustrate their ideas on } \\
\text { drawing boards or to brainstorm any of their thoughts. }\end{array}$ & $\begin{array}{l}\text { Refreshments, water bottles, candies, and cookies. } \\
\text { Audio recorder. } \\
\text { Antiseptic wipes to clean clipboard at the end of } \\
\text { each interview prior to the next participant. }\end{array}$ \\
\hline $\begin{array}{l}\text { Participants' feedback about } \\
\text { interview method }\end{array}$ & $\begin{array}{l}\text { Questions designed to obtain feedback from the } \\
\text { participants about their experiences during involvement in } \\
\text { the research and of the methods used during the interview. }\end{array}$ & \\
\hline Interview close & $\begin{array}{l}\text { Participants were asked if they had any queries regarding } \\
\text { the interview or the study. }\end{array}$ & \\
\hline
\end{tabular}

Note: Acapella ${ }^{\circledR}$, Smiths Medical, St Paul, MN, USA.

That's what I like about the diabetes monitor. My parents can

check it and then they don't get on at me so much if they know

I might get caught out if I don’t do it. [Male, 20 years]

A common theme arising among the participants was their desire to be treated like adults and to be more involved in the management of their health care needs (32 refs). It was suggested that technology could enable individuals to better manage their health care needs and aid other aspects of "growing up", such as education and relationships. These objectives align with the adolescent goal of autonomy (Figure 1) and suggest a potential role for medical devices in supporting adolescent transition services.

"Having a voice" (23 refs) was an important aspect of personal assimilation of independence but did not occur as much as participants would like:

They should really talk to us, about what we want. At the end

of the day it's us who use it every day. [Male, 20 years]

This supports previous research, in which adolescents with CF (13-16 years old) expressed a desire to be seen on their own during consultations. ${ }^{22}$ The adolescents in our study, from both pediatric and adult clinics, felt that consultations were directed at parents and reported that, if the acapella ${ }^{\circledR}$ could be redesigned to enable self-monitoring (63 refs), it might be a more useful tool. It was suggested that this would enable them to increase responsibility for their health care and improve communication with health care staff and parents.

It was also suggested that remote monitoring technologies might enable users to test their airway clearance technique more frequently, without having to visit hospital (43 refs). One improvement suggested was implementation of a device that could measure how the acapella ${ }^{\circledR}$ was being used that would then send this information for review by clinicians, potentially reducing clinic time and increasing time in consultations for discussion of health and lifestyle (15 refs):

If you could do that so it registered and then you could email it to the doctors or the CF team, so instead of doing it [physiotherapy] here and then going away for three months ... and it's different here anyway from at home ... so there could be a continual record. [Mother of adolescent CF patient] 
The data suggest that there is a relationship between respecting adolescent independence and capabilities and the goals of adolescence (Figure 1) and that medical device design and use may affect and be affected by adolescent maturity. This suggests that good design could facilitate the transition to autonomy, which poor design could hinder.

\section{Motivation and incentive}

Twelve of the 20 participants expressed that their motivation (30 refs) to carry out physiotherapy is sometimes low, largely due to the repetitive nature of the task:

I find it boring and I'm looking at the time all the time,

every 5 minutes and that. [Male, 19 years]

Ullrich describes the intrusiveness of treatment and recommends that health care systems should be evaluated to identify factors that facilitate patient adherence and reduce burden. ${ }^{23}$ The interview data support this previous work, indicating that the monotonous and intrusive nature of medical device use plays a role in adherence.

Younger participants reported awareness of the long-term benefits of physiotherapy but acknowledged that it was not always an incentive in the short term. Older adolescents were more motivated in the short term to perform their physiotherapy, perhaps as the result of more appreciation of long-term outcomes. This capacity to comprehend long-term outcomes is associated with the adolescent goal of abstract thinking; development of this goal contributes to changes in perspective and affects behavior change. ${ }^{24}$

Participants aged 16 years and younger revealed a desire to be entertained during physiotherapy. Gaming and music were suggested as ways that devices could achieve this (24 refs):

On the website there could be games when you have to jump and stuff but you'd have to do that by blowing in your acapella ${ }^{\circledR}$. It could be racing and it could be sensor activated so when you move it to the left and blow it moves it to the left and when you move it to the right and blow it moves to the right. [Male, 11 years]

These findings suggest the growth of competency and maturity during adolescence (Figure 1), illustrating how adolescents can understand the consequences of nonadherence, a capacity that children are unlikely to have. The data also suggest that medical devices could potentially support adolescents in developing this competency through motivation and engagement in self-management.

A lack of variation and choice about device options, aesthetics, and interactions may also contribute to lack of satisfaction and poor adherence:
[The device is] just so boring ... like, you want to be able to

change things when you want. [Female, 14 years]

Customization and disguise were suggested as ways that the acapella ${ }^{\circledR}$ could be modified to be more socially acceptable (ten participants). Older participants (18-20 years) were less likely than younger participants to consider aesthetics to be important; however, they did acknowledge that this aspect may be important to younger users as they learn to live with $\mathrm{CF}$ (five refs):

For some people personalizing your device might help.

Probably for younger people, you know like younger

teenagers and kids, it makes it easier. [Male, 20 years]

Choice was talked about in relation to "normalization" of the medical devices and chronic condition management, and is a concept that has previously been linked with identity formation in adolescents ${ }^{26}$ (Figure 1).

The relationship of motivation and adherence incentive to the goals of adolescence, as suggested by the data, are shown in Figure 1, and the data further suggest that medical device design can be related to adolescent identity formation and self-determination. Furthermore, adherence has been shown to be influenced by the ability of adolescents to think abstractly about future consequences, an ability that is indicative of increasing maturity. ${ }^{25}$

\section{Fitting in with adolescent life}

The interviews revealed that adolescents value ease and efficiency of use:

You just want to get on with it at the end of the day, as quick as possible without any faffing. [Female, 16 years]

Improved efficiency was cited as a factor that would help a device "fit in" with daily life (43 refs). This was mentioned along with frequency and duration of use and correct technique (eg, posture, breathing routine), with some participants reporting that a feedback function on the device might improve these use issues. In this study, a lack of feedback also contributed to a lack of perceived benefit, which supports the finding of George et al, that a lack of negative impact from skipped treatments and failure to achieve symptom relief contribute to nonadherence. ${ }^{27}$

Convenience (22 refs) and discreteness (12 refs) were also significant factors:

If it's not so noticeable ... it could be more disguised really. Or if it had a case, then you wouldn't be able to see what it is anyway. I'd feel more comfortable with it. [Male, 19 years] 
An important concept is how the device can be integrated into the user's life while not drawing attention to the user's condition. The acapella ${ }^{\circledR}$ was compared unfavorably to blood glucose monitors, which were considered more discrete and socially acceptable, examples given included the provision of a case to put the device and disposables in, that they were more common and people knew what they were used for and that they could be more easily hidden and carried in a pocket or bag (five participants).

Half of the participants had at some point abandoned the acapella ${ }^{\circledR}$ to test out other devices and airway clearance techniques and stated that this was because it did not fit in with their lifestyle:

It was just that I got taught a new way of doing my physio and it seemed to work better for me. I'm not very productive most of the time and just doing that seemed to fit in better with my life because you can do it anywhere rather than taking your acapella ${ }^{\circledR}$ with you all the time. [Male, 20 years]

This supports the case that adherence to medical device use can be affected by whether or not it "fits into" the adolescent's life. This theme is closely tied with the goal of autonomy of the adolescent, their management of personal health behaviors, and how the role of a device in a young persons life can influence identity formation.

\section{Device use in the community}

Specific locations of use were discussed by 17 participants (43 refs). Six male participants admitted to only using their device at home and not in other environments. In contrast, none of the females stated that use of their acapella ${ }^{\circledR}$ was restricted to the home and disclosed locations of use that included school, in the car, and at a boyfriend's or friend's house. This links to the themes of privacy (17 refs) and social acceptance and suggests sex differences associated with adolescent medical device use.

As adolescents become increasingly independent, use environments will become more varied. Older adolescents in this study tended to have wider spheres of usage than younger adolescents, including school and social trips and overnight stays at friends'/partners' houses. The challenges of leaving home to go to university were also mentioned. The impact of this increasing independence was described by a parent:

I think from your perspective, being a young teenager, you need a bit more adult supervision. When you're getting older, you'll probably want a bit more independence, but also you may want to use it away from home. The more you become a teenager, the more after school activities you're doing, less time you have at home, you might find opportunities when you can do it away from home. [Father of adolescent CF patient]

Seven participants identified holidays as an issue for adherence. Some perceived holidays as a "break" from airway clearance and reported that they sometimes did not take their acapella ${ }^{\circledR}$ away with them. Specific issues with travel were the size, weight, and portability of the device:

It's a pain to pack everything. When you've got a maximum weight on your luggage, you've got to be careful. [Female, 20 years]

There are many complex issues that affect how adolescents use medical devices in the community. Many factors appear to affect adherence, including stage of adolescence, sex, confidence, and lifestyle. This theme links to the adolescent goals of maturity, assimilation of autonomy, and self-determination (Figure 1).

\section{Information}

The exchange of information (24 refs) was a topic raised during the interviews, particularly in relation to monitoring and independence.

Information pathways rely heavily on users having good relationships with health care professionals, and it was suggested by the adolescents interviewed that this could be facilitated by medical devices. Participants suggested that sharing information from the device with health care staff could improve communication with health care professionals:

It would be a help towards, when you come here [the hospital] and they say your lung function is down. ... You can say, "But look at this, I've been breathing like this." [Female, 19 years]

The need for training was discussed by six participants (12 refs), and was mainly related to new users learning to use the acapella ${ }^{\circledR}$ :

If someone puts it in front of you without telling you much, they just expect you to know. That's what happened with me but if they tell you more it's better for being able to use it, I didn't get told very much. [Male, 18 years]

Seven participants reported concerns about long-term use of the device and deterioration of technique when away from the clinic. They suggested that online resources 
with help pages and technique demonstrations in addition to videos and games would enable them to check their technique:

Sometimes you're not sure, even though you have been shown how to do it, if I've not used it for a couple of weeks and I forget, I have to ring up and ask how to do it. It would be quite good if there was something about how to do it on the thing or online. [Male, 19 years]

These admissions suggest that users of the acapella ${ }^{\circledR}$ device need ongoing training support to maintain correct technique. Awareness of the importance of this issue shows that the participants had the capacity to evaluate their physiotherapy technique and the competence to understand the benefits of correct and regular physiotherapy.

The participants frequently made reference to wider issues associated with social acceptance, social awareness of $\mathrm{CF}$, and society (66 refs). Some participants experienced difficulties at school and suggested that improved information provision could have a positive impact on social acceptance and awareness of CF, in particular, and of medical conditions generally:

There needs to be more information and get people to know about it $[\mathrm{CF}]$ better ... they just don't get what I need. [Female, 14 years]

\section{Discussion}

Considering the research questions stated at the beginning of this study, it appears that, in the case of the acapella ${ }^{\circledR}$, the device is appropriate for adolescent use but requires modification to fully meet adolescents' needs. Participants reported design issues associated with personal and social aspects of use, providing evidence that design can negatively affect adolescent adherence. Currently, the device does not play a large role in the management of chronic conditions, but this study has identified a number of ways that patient users of the device thought that changes in design could improve adherence, self-management, and adolescent progression into adulthood.

\section{Adolescent medical device use}

This study supports the work of Withers ${ }^{6}$ in showing that adolescents with CF want to be able to be independent and control the management of their condition, and suggests that appropriately designed devices can be a tool that supports adolescent independence and comanagement of conditions. ${ }^{11}$ The data elicited from participants also support the findings of George et al, who found that adolescents approaching adulthood tend to have an increasing awareness of their condition and understanding of the challenges of adhering to treatment. ${ }^{27}$

Motivation and incentive appear to be key issues of adolescent medical device use, and this finding aligns with

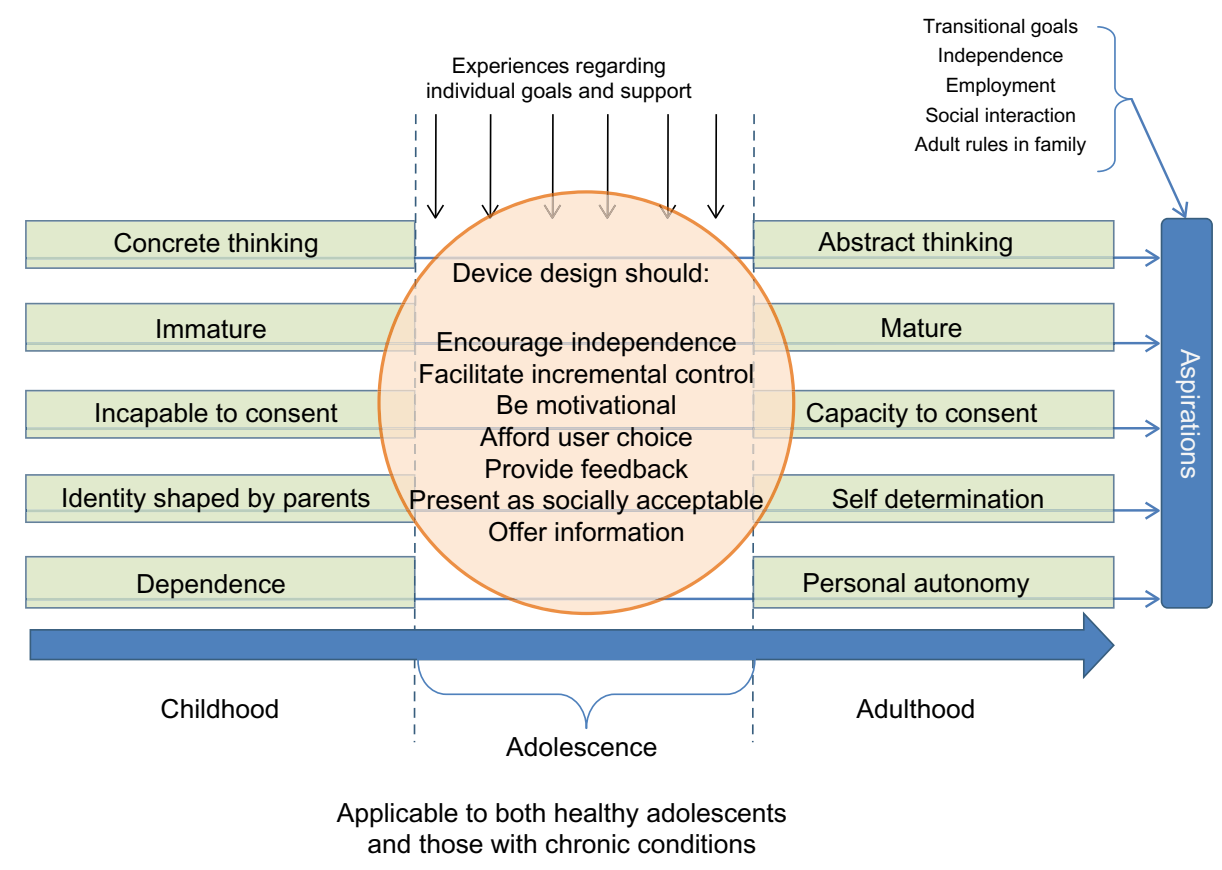

Figure 3 Medical devices as facilitators for achievement of adolescent goals and adherence. 
established theories of medical and assistive technology nonuse and abandonment. ${ }^{28}$ The work of Christenson et al has previously demonstrated health care benefits when simulation and gaming are used in adolescent health care interventions, ${ }^{29}$ a concept which is reinforced by the adolescent perspectives within this study. Further work should be conducted to consider how medical devices can be designed to take advantage of these technologies.

Adolescents want their devices to physically and socially fit in to their everyday lives. They also expressed a need for medical devices to support them and their families to integrate treatment into the daily routine, whilst enabling them to maintain optimal adherence to long term therapies. This study shows that design should take account of the realities of users' lives, so that they are willing to carry and use their devices in a variety of settings, and ensure that devices are designed to fit into everyday routines to maximize benefits and efficiency of use. This supports the work of Withers, who advocates systems that assist patients with "scheduling and time management, allowing some degree of choice, setting realistic goals, negotiating treatments based on amount of time required."

\section{Adolescent goals}

Figure 3, which is a modified version of the adolescent transition diagram shown in Figure 1, provides an overview of the role of technology in this transitional period. The middle section illustrates how medical device design has the potential to benefit adolescents with a chronic condition. In particular, device design should 1) contribute to improved adherence and self-management and 2) assist the transition from child to adult. This diagram of adolescent development visually articulates how successful transition from childhood to adulthood "should promote autonomy and responsibility with respect to one's health" 16 and presents the ways that medical device design can provide tools and mechanisms to support the young user in this process.

This model can be utilized by adolescent health practitioners, academics, and health technology developers to inform their understanding of adolescent medical device requirements, preferences, and use with regards to adherence and personal development.

\section{Limitations}

This study took place within CF hospital clinics and interviews were sometimes interrupted or prematurely ended due to clinical scheduling. Another environment, in which interviews would not have been disturbed, may have been preferable.

Another limitation of this study is that, although participants were advised that there were no wrong answers and their responses were not being reported to clinicians or parents, there may still have been an element of censorship with the discussions, especially due to the interviews taking place in the clinical environment.

This study was not hypothesis driven and, as such, the impact of device design on quality of life was not anticipated, emerging only during the analysis of the data. Future work in this area would benefit from the additional use of a validated tool such as the Cystic Fibrosis Questionnaire Revised ${ }^{30}$ to support findings regarding medical device design and quality of life.

\section{Conclusion}

This study shows that:

- Adolescent participants are able to critically appraise their medical technologies and describe the role they have in chronic condition management.

- Medical device design can be linked to both adherence and achievement of adolescent goals.

- Medical device use is a multifarious construct and a wide range of factors will influence adherence.

This study investigated the psychosocial needs of adolescent users of medical devices in the daily management of $\mathrm{CF}$ and shows that an improved understanding of these needs is required to inform the design of medical devices for this user group. The provision of medical devices that have been designed to meet adolescent requirements will not only improve adherence and health outcomes, but will also support adolescents with chronic conditions to successfully transition into adulthood.

\section{Acknowledgments}

We would like to express our thanks to the staff and patients within the cystic fibrosis clinics in the Queen's Medical Centre and City Hospital, Nottingham, UK, without whose help this study would not have been possible. The authors acknowledge support of this work through the MATCH Programme (EPSRC Grant GR/S29874/01), although the views expressed are entirely their own.

\section{Disclosure}

The authors report no conflicts of interest in this work. The contents of this paper have not been commissioned and have been externally peer reviewed. 


\section{References}

1. Martin JL, Norris BJ, Murphy E, Crowe JA. Medical device development: the challenge for ergonomics. Appl Ergon. 2008;39:271-283.

2. Geljins AC, Killelea B, Vitale M, Mankad V, Moskowitz A. The dynamics of pediatric device innovation: putting evidence in context. In: Field MJ, Tilson H, editors. Safe Medical Devices for Children. Washington, DC: The National Academies Press; 2005:302-326.

3. Suris JC, Michaud PA, Viner R. The adolescent with a chronic condition. Part I: developmental issues. Arch Dis Child. 2004;89(10):938-942.

4. Thorne SE. The science of meaning in chronic illness. Int J Nurs Stud. 1999;36(5):397-404.

5. Lang AR. Medical Device Design for Adolescents [doctoral thesis]. Nottingham: University of Nottingham; 2012.

6. Withers AL. Management issues for adolescents with cystic fibrosis. Pulm Med. 2012;2012:ID 134132.

7. Catalano RF, Fagan AA, Gavin LE, et al. Worldwide application of prevention science in adolescent health. Lancet. 2012;379(9826): $1653-1664$.

8. Suris JC, Michaud PA, Akre C, Sawyer SM. Health risk behaviors in adolescents with chronic conditions. Pediatrics. 2008;122(5): e1113-e1118.

9. Bowsworth HB, Oddone EZ, Weinberger M, editors. Patient Treatment Adherence: Concepts, Interventions, and Measurement. Mahwah, NJ: Lawrence Erlbaum Associates, Inc., Publishers; 2008:5.

10. Carter B. Tick box for child? The ethical positioning of children as vulnerable, researchers as barbarians and reviewers as overly cautious. Int J Nurs Stud. 2009;46(6):858-864.

11. Lemly DC, Weitzman ER, O'Hare K. Advancing healthcare transitions in the medical home: tools for providers, families and adolescents with special healthcare needs. Curr Opin Pediatr. 2013;25(4):439-446.

12. Blum RW. Chronic illness and disability in adolescence. JAdoles Health. 1992;13(5):364-368.

13. Orenstein DM. Cystic Fibrosis. A Guide for Patient and Family. 3rd ed. Philadelphia, PA: Lippencott Williams \& Wilkins; 2004:xi.

14. Bregnballe V, Schiøtz PO, Boisen KA, Pressler T, Thastum M. Barriers to adherence in adolescents and young adults with cystic fibrosis: a questionnaire study in young patients and their parents. Patient Prefer Adherence. 2011;5:507-515.

15. Pendleton DA, David TJ. The compliance conundrum in cystic fibrosis. J R Soc Med. 2000;93 Suppl 38:9-13.

16. Kriendler JL, Miller VA. Cystic fibrosis: addressing the transition from pediatric to adult-oriented health care. Patient Prefer Adherence. 2013;7:1221-1226.
17. Lang AR, Martin JL, Sharples S, Crowe JA. Enabling adolescents to participate in the design and improvement of medical devices. In: Proceedings of the 17th World Congress on Ergonomics (IEA2009), Beijing, People's Republic of China, August 9-14, 2009.

18. Keane D, Lang AR, Craven M, Sharples S. The use of vignettes for conducting healthcare research. In: Duffy VG, editor. Advances in Human Aspects of Healthcare. Boca Raton, FL: CRC Press; 2012:451-460.

19. Seale C, Silverman D. Ensuring rigour in qualitative research. Eur $J$ Public Health. 1997;7(4):379-384.

20. Hahn C. Coding. In: Doing Qualitative Research Using Your Computer: A Practical Guide. London: SAGE Publications Ltd; 2008:1-16.

21. Lang AR, Martin JL, Sharples S, Crowe JA. The effect of design on the usability and real world effectiveness of medical devices: a case study with adolescent users. Appl Ergon. 2013;44(5):799-810.

22. Zack J, Jacobs CP, Keenan PM, et al. Perspectives of patients with cystic fibrosis on preventive counseling and transition to adult care. Pediatr Pulmonol. 2003;36(5):376-383.

23. Ullrich G. Lapses in adherence: explaining patients' reasons. 13th European Health Forum Gastein; October 6-9, 2010; Bad Hofgastein, Austria.

24. Steinberg L. Cognitive Transitions. In: Adolescence. 6th ed. New York: McGraw Hill; 2002:58-65.

25. Taddeo D, Egerdy M, Frappier JY. Adherence to treatment in adolescents. Paediatr Child Health. 2008:13(1):19-24.

26. Kirk S. How children and young people construct and negotiate living with medical technology. Soc Sci Med. 2010;71(10):1796-1803.

27. George M, Rand-Giovannetti D, Eakin MN, Borrelli B, Zettler M, Riekert KA. Perceptions of barriers and facilitators: self-management decisions by older adolescents and adults with CF. J Cyst Fibros. 2010;9(6):425-432.

28. Wessels R, Dijcks B Soede M, Gelderblom GJ, De Witte L. Non-use of provided assistive technology devices, a literature overview. Technology and Disability. 2003;15(4):231-238.

29. Christenson KM, Williams AJ, Williams RH, et al. Can a simulation game change cystic fibrosis patients' attitudes toward treatment adherence? Games Health J. 2012;1(2):129-133.

30. Quittner AL, Sawicki GS, McMullen A, et al. Psychometric evaluation of the Cystic Fibrosis Questionnaire-Revised in a national sample. Qual Life Res. 2012;21(7):1267-1278.
Patient Preference and Adherence

\section{Publish your work in this journal}

Patient Preference and Adherence is an international, peer-reviewed, open access journal focusing on the growing importance of patient preference and adherence throughout the therapeutic continuum. Patient satisfaction, acceptability, quality of life, compliance, persistence and their role in developing new therapeutic modalities and compounds to

\section{Dovepress}

optimize clinical outcomes for existing disease states are major areas of interest. This journal has been accepted for indexing on PubMed Central. The manuscript management system is completely online and includes a very quick and fair peer-review system. Visit http://www.dovepress.com/ testimonials.php to read real quotes from published authors. 